\title{
Modifikasi Desain Struktur Gedung Hotel Holiday Inn Express Surabaya dengan Menggunakan Sistem Rangka Bresing Eksentrik
}

\author{
Lailatul Fitriyah, Priyo Suprobo, dan Endah Wahyuni \\ Departemen Teknik Sipil, Fakultas Teknik Sipil dan Perencanaan, Institut Teknologi Sepuluh Nopember (ITS) \\ e-mail: priyo@ce.its.ac.id,endah@ce.its.ac.id
}

\begin{abstract}
Abstrak-Perencanaan gedung hotel Holiday Inn Express Surabaya akan dilakukan modifikasi perancangan menggunakan struktur baja dengan metode SRBE (Sistem Rangka Bresing Eksentrik). SRBE merupakan sebuah sistem bresing eksentrik yang memiliki link dan berfungsi sebagai pendisipasi energi ketika struktur menerima beban lateral. Perhitungan modifikasi perencanaan struktur gedung hotel Holiday Inn Express Surabaya menggunakan sistem rangka bresing eksentrik (SRBE) telah dilakukan. Dimana perhitungan struktur mengacu pada SNI 1729-20015 "Tata Cara Perencanaan Struktur Baja Untuk Bangunan Gedung", SNI 1726-2012 "Tata Cara Perencanaan Ketahanan Gempa Untuk Bangunan Gedung", SNI 2847-2013 "Tata Cara Perencanaan Struktur Beton Untuk Bangunan Gedung” dan "Peraturan Pembebanan Indonesia Untuk Gedung" PPIUG 1983. Pemodelan dan analisis struktur dilakukan dengan program bantu SAP 2000. Dari analisa dan hasil perhitungan diperoleh struktur sekunder dan primer: pelat lantai menggunakan bondek SUPER FLOOR DECK $\mathrm{t}=0,75 \mathrm{~mm}$, untuk lantai top atap dan lantai $1 \mathrm{t}=90 \mathrm{~mm}$, lantai atap dan lantai 2-14 $\mathrm{t}=110 \mathrm{~mm}$, balok anak terdapat 4 macam dimensi yang digunakan, dimensi untuk lantai top atap WF $350 \times 175 \times 6 \times 9$, lantai atap WF $450 \times 200 \times 9 \times 14$, lantai $2-14$ WF $500 \times 200 \times 9 \times 14$, lantai 1 WF 400x200x8x13, sedangkan balok induk terdapat 4 macam dimensi juga yang digunakan, dimensi untuk lantai top atap WF $400 \times 200 \times 8 \times 13$, lantai atap WF $500 \times 200 \times 9 \times 14$, lantai $2-14$ WF $600 \times 200 \times 10 \times 15$, lantai 1 WF $600 \times 200 \times 11 \times 17$, untuk dimensi kolom lantai 1-8 digunakan CFT 700x700x25 dan CFT 600x600x25 dimensi kolom lantai 9-top atap, link terdapat 2 macam dimensi yang digunakan yaitu WF $400 \times 200 \times 8 \times 13$ untuk lantai atap-top atap dan WF $500 \times 200 \times 10 \times 16$ untuk lantai 1-14, dimensi balok luar link yang digunakan sama dengan dimensi link, dimesi bresing yang digunakan WF 250x250x9x14 untuk lantai atap-top atap dan WF $300 \times 300 \times 10 \times 15$ untuk lantai 1-14. Pondasi struktur menggunakan tiang bor (borepile) diameter $120 \mathrm{~cm}$ dengan kedalaman $25 \mathrm{~m}$ dan tulangan yang digunakan adalah 26 D25 dengan sengkang D16-45 mm.
\end{abstract}

Kata Kunci-Sistem Rangka Bresing Eksentris, Plastifikasi, Link.

\section{PENDAHULUAN}

\section{A. Latar Belakang}

Gedung hotel Holiday-Inn Express Surabaya yang terletak di Jalan Kedungdoro VI No. 54-58 Sawahan, Surabaya merupakan gedung yang terdiri dari 16 lantai dan struktur bangunan yang digunakan adalah struktur bangunan beton bertulang. Kondisi tanah pada daerah yang dibangun termasuk tanah lunak sehingga membutuhkan berat bangunan yang seringan mungkin namun memiliki kekuatan struktur yang sebesar mungkin untuk menahan gaya lateral (gempa dan angin).
Perencanaan suatu struktur bangunan tahan gempa merupakan suatu kebutuhan yang tidak dapat dihindari. Tujuan desain bangunan tahan gempa adalah untuk mencegah terjadinya kegagalan struktur dan kehilangan korban jiwa. Sehingga dalam merancang suatu bangunan tahan gempa harus mengutamakan keselamatan dan kenyamanan, dimana kegagalan direncanakan hanya terjadi pada daerah non structural. Oleh karena itu struktur bangunan gedung hotel Holiday-Inn Express Surabaya yang semula menggunakan struktur beton bertulang akan dimodifikasi menggunakan struktur baja.

Baja memiliki sifat daktail (tidak getas), dimana baja mampu berdeformasi tanpa runtuh secara tiba-tiba apabila terjadi beban yang berlebihan. Ini memberikan cukup waktu untuk evakuasi bila terjadi gempa. Konstruksi baja juga memiliki berat yang relatif lebih ringan dari pada material lain tetapi juga memiliki kemampuan yang cukup tinggi, hampir tidak memiliki perbedaan nilai muai dan susut, dan dalam hal pelaksanaan jauh lebih cepat dibanding material lain [1].

SRBE mempunyai nilai daktilitas yang lebih tinggi dibandingkan dengan SRBK. Tingginya nilai daktilitas pada SRBE diakibatkan oleh adanya elemen link yang berfungsi sebagai pendisipasi energi ketika struktur menerima beban gempa. Pendisipasian energi ini diwujudkan dalam bentuk plastifikasi pada elemen link tersebut.

Berdasarkan kondisi tanah di lapangan dan hasil dari perhitungan analisa kategori desain seismik adalah bangunan termasuk dalam kategori desain $\mathrm{D}$, maka salah satu sistem rangka baja yang dapat digunakan adalah sistem rangka bresing eksentrik (SRBE).

\section{B. Perumusan Masalah}

1. Bagaimana merencanakan struktur sekunder yang meliputi pelat, balok anak dan tangga?

2. Bagaimana merencanakan struktur primer yang meliputi balok, kolom, bresing eksentrik dan link?

3. Bagaimana memodelkan dan melakukan analisis struktur dengan program bantu SAP 2000 v14?

4. Bagaimana merencanakan sambungan?

5. Bagaimana merencanakan pondasi?

6. Bagaimana mengilustrasikan hasil perencanaan struktur dalam gambar teknik?

\section{Batasan Masalah}

Dalam penyusunan Studi ini diberikan beberapa batasan masalah sebagai berikut :

1. Menggunakan SNI 03-1729-2015 tentang Tata Cara Perencanaan Struktur Baja Untuk Bangunan Gedung. 
2. Menggunakan SNI 1726-2012 tentang Tata Cara Perencanaan Ketahanan Gempa Untuk Struktur Bangunan Gedung dan Non Gedung.

3. Tidak menghitung anggaran biaya.

4. Tidak membahas metode pelaksanaan proyek

5. Tidak mempertimbangkan sistem sanitasi dan instalasi listrik gedung.

6. Tidak membahas dari segi arsitektural.

7. Tidak memperhitungkan basement.

\section{TINJAUAN PUSTAKA}

\section{A. Umum}

Sistem Rangka Bresing Eksentris (SRBE) adalah suatu sistem rangka baja yang terdiri dari balok, kolom, dan pengaku dimana pada ujung dari bagian pengakunya terdapat suatu elemen yang menggabungkan antar bagian dari sistem rangka yang disebut link. Karakteristik yang membedakan SRBE dengan desain struktur tahan gempa SRPM dan SRBK adalah adanya penghubung yang terdapat pada setidaknya salah satu ujung dari bresing yang disebut sebagai link [2].

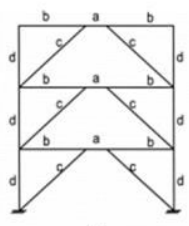

(a)

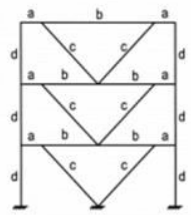

(c)

$a=$ Link

$b=$ beam segment outside of $L$ ink

$c=$ diagonal brace
$d=$ column
Gambar 2.1 Konfigurasi Link pada Beberapa Sistem Portal [3].
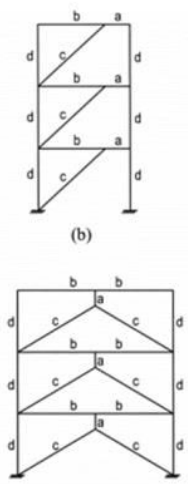

(d)
Pada gambar.2 dijelaskan tentang kurva hubungan antara gaya lateral dengan perpindahan yang terjadi pada SRBK, SRBE, dan SRPM. SRBE dapat memberikan perilaku struktur yang di harapkan saat terjadi gempa yaitu terlalu kaku seperti halnya SRBK tetapi juga tidak terlalu memiliki deformasi yang besar seperti SRPM.

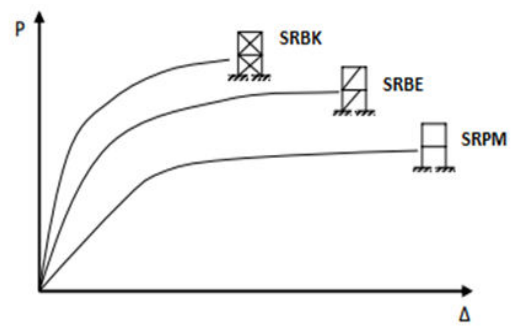

Gambar 2.2 Perbedaan perilaku tiga model sistem rangka baja [4]

\section{B. Sudut Rotasi Link Beam}

Sudut rotasi link beam adalah sudut inelastis antara link beam dan balok di samping link ketika besarnya total story $d r i f t$ sama dengan besarnya desain story drift, $\theta$. Pada desain struktur penahan gempa dengan SRBE perlu diperhitungkan besar rotasi plastis yang akan dialami oleh link. Pada tahap ini lebih mudah menggunakan mekanisme disipasi energi (juga disebut mekanisme kehancuran). Gambar 2.9 menunjukkan mekanisme kehancuran dari SRBE. Pada setiap kasus $\theta$ merupakan besar penyimpangan yang terjadi pada rangka, besar penyimpangan pada sendi plastis terhadap balok juga disimbolkan $\theta$. Untuk SRBE besar dari kebutuhan rotasi link $(\gamma)$ harus lebih besar dari $\theta$, dengan perumusan:

$$
\gamma=\frac{\mathrm{L}}{\mathrm{e}} \boldsymbol{\theta}
$$
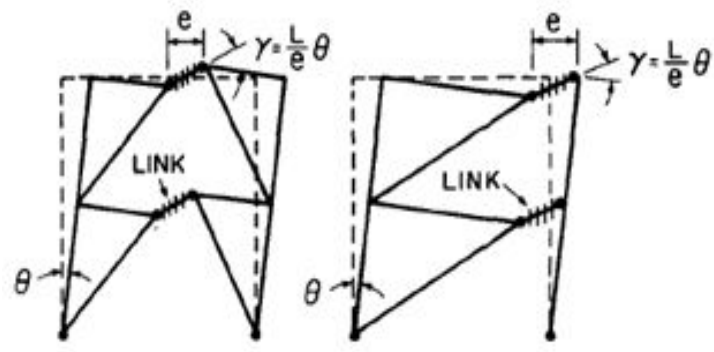

Gambar 2.3 Sudut Rotasi Link Beam [4]

\section{METODOLOGI}

\section{A. Umum}

Langkah - langkah pengerjaan proyek akhir ini akan dilakukan seperti diagram alir berikut.

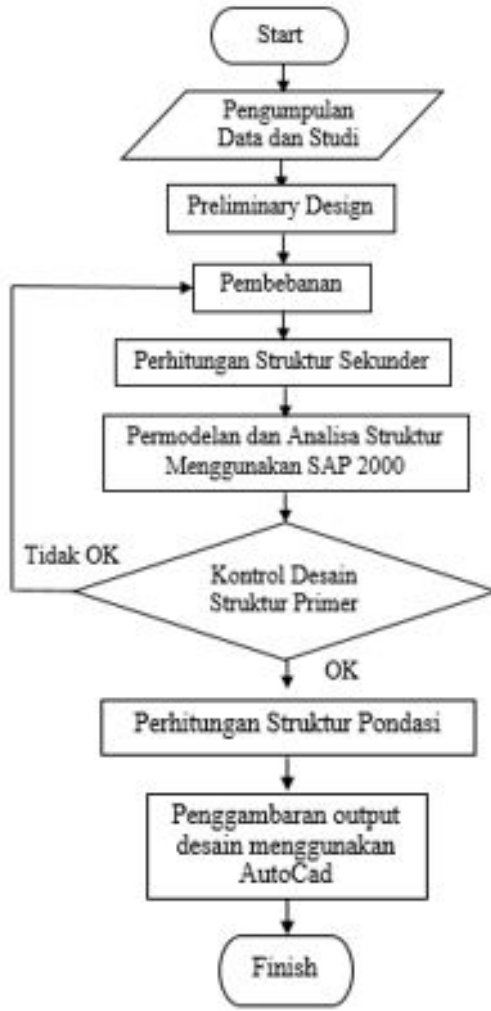

Gambar 3.1 Diagram Alir Metodologi.

Penyelesaian Studi

\section{PERENCANAAN STRUKTUR SEKUNDER}

\section{A. Pelat Lantai Hotel Holiday In Express Surabaya}

Tabel 4.1

Rekap Dimensi dan Penulangan Pelat

\begin{tabular}{ccc}
\hline \hline LANTAI & $\begin{array}{c}\text { TEBAL } \\
(\mathrm{cm})\end{array}$ & TULANGAN \\
&
\end{tabular}




\begin{tabular}{ccc}
\hline Top atap & 9 & M8-200 \\
Atap & 11 & M9,5-200 \\
$2-14$ & 11 & M10-175 \\
1 & 9 & M9-200 \\
\hline \hline
\end{tabular}

B. Balok Anak

Tabel 4.2

Rekap Dimensi Balok Anak

\begin{tabular}{cc}
\hline \hline LANTAI & PROFIL YANG DIGUNAKAN \\
\hline Top atap & WF $350 \times 175 \times 6 \times 9$ \\
Atap & WF $450 \times 200 \times 9 \times 14$ \\
$2-14$ & WF $500 \times 200 \times 9 \times 14$ \\
1 & WF $400 \times 200 \times 8 \times 13$ \\
\hline \hline
\end{tabular}

C. Balok Penumpu Lift

- Tipe lift: Passenger Elevators

- Merek : HYUNDAI

- Kapasitas : 15 Orang / $1000 \mathrm{~kg}$

- Lebar pintu (opening width) : $900 \mathrm{~mm}$

- Dimensi ruang luncur

(hoistway inside) 2 Car $\quad: 4800 \times 2150 \mathrm{~mm}^{2}$

- Dimensi sangkar (Car size)

(hoistway inside) 2 car $\quad: 4200 \times 2100 \mathrm{~mm}^{2}$

- Dimensi ruang mesin : $4400 \times 3850 \mathrm{~mm}^{2}$

- Dimensi sangkar (Car size)

Internal

: $1600 \times 1500 \mathrm{~mm}^{2}$

Eksternal

: $1660 \times 1655 \mathrm{~mm}^{2}$

- Beban reaksi ruang mesin:

$\mathrm{R}_{1}=5450 \mathrm{~kg}$

$\mathrm{R}_{2}=4300 \mathrm{~kg}$

Tabel 4.3

Rekap Dimensi Balok Lift

\begin{tabular}{cc}
\hline \hline ELEMEN & PROFIL YANG DIGUNAKAN \\
\hline Pembagi & WF $100 \times 50 \times 5 \times 7$ \\
Penumpu & WF $400 \times 200 \times 7 \times 11$ \\
\hline \hline
\end{tabular}

D. Perencanaan Tangga

- Tinggi lantai $=4,8 \mathrm{~m}$

- Panjang bordes $=2,8 \mathrm{~m}$

- Tinggi bordes $=2,4 \mathrm{~m}$

- Lebar bordes $=1,3 \mathrm{~m}$

- Panjang anak tangga $(1 / 2 \mathrm{~L}$ bordes $)=1,3 \mathrm{~m}$

- Lebar injakan (i) $=28 \mathrm{~cm}$

- Tinggi injakan $(\mathrm{t})=20 \mathrm{~cm}$

- Lebar pegangan tangga $=5 \mathrm{~cm}$

Tabel 4.4

Rekap Dimensi Balok Tangga

\begin{tabular}{cc}
\hline \hline ELEMEN & PROFIL YANG DIGUNAKAN \\
\hline Pengaku anak tangga & L $50 \times 50 \times 5$ \\
Pengaku bordes & WF $100 \times 50 \times 5 \times 7$ \\
Balok utama tangga & WF $200 \times 100 \times 5,5 \times 8$ \\
Balok penumpu bordes & WF 200 $100 \times 5,5 \times 8$ \\
\hline \hline
\end{tabular}

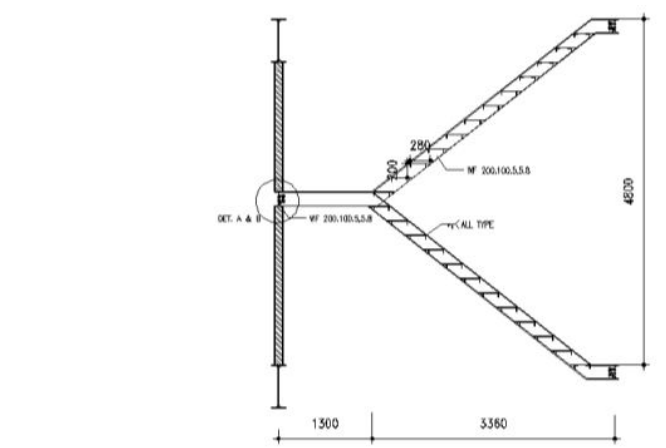

Gambar 4.1 Potongan Tangga.

\section{PEMODELAN STRUKTUR}

\section{A. Umum}

Pemodelan struktur pada Studi ini menggunakan sistem rangka bresing eksentrik (SRBE). Struktur yang direncanakan adalah bangunan hotel yang terdiri dari 16 lantai hotel dengan total tinggi struktur 58,25 meter. Denah dari struktur yang ada dalam permodelan Studi penulis adalah sebagai berikut:

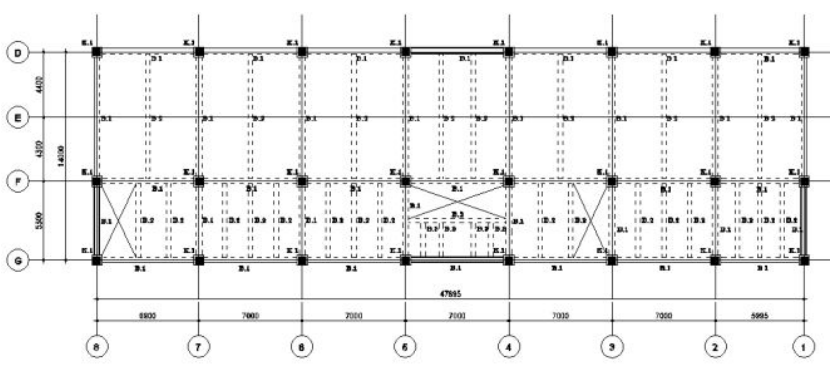

Gambar 5.1 Denah Struktur Hotel Holiday Inn Express Surabaya.

\section{B. Pembebanan}

Rincian pembebanan untuk beban mati adalah sebagai berikut:
a. Pelat atap
b. Pelat lantai hotel
$=79,53 \mathrm{~kg} / \mathrm{m}^{2}$
$=128 \mathrm{~kg} / \mathrm{m}^{2}$
c. Pelat lantai koridor
$=128 \mathrm{~kg} / \mathrm{m}^{2}$

Rincian pembebanan untuk beban hidup adalah sebagai berikut :
a. Lantai atap
$=97,64 \mathrm{~kg} / \mathrm{m}^{2}$
b. Lantai hotel
$=195,28 \mathrm{~kg} / \mathrm{m}^{2}$
C. Lantai koridor atau lobi $=487,18 \mathrm{~kg} / \mathrm{m}^{2}$

\section{Kombinasi Pembebanan}

Kombinasi pembebanan yang dipakai pada struktur gedung ini mengacu pada SNI 1729:2012 sebagai berikut:

- $1 \mathrm{D}+1 \mathrm{~L}$

- $1,4 \mathrm{D}$

- $1,2 \mathrm{D}+1,6 \mathrm{~L}$

- $1,2 \mathrm{D}+1 \mathrm{~L}$

- $1,2 \mathrm{D}+1 \mathrm{Ex}+1 \mathrm{~L}$

- $1,2 \mathrm{D}+1 \mathrm{Ey}+1 \mathrm{~L}$

- $0,9 \mathrm{D}+\mathrm{Ex}$

- $0,9 \mathrm{D}+\mathrm{Ey}$

Keterangan :

D : beban mat

L : beban hidup lantai

$\mathrm{E}$ : beban gempa yang dinyatakan dalam arah $\mathrm{X}$ dan $\mathrm{Y}$ 


\section{Kontrol Desain}

1. Kontrol Penerimaan Pemodelan

Untuk membuktikan hasil pemodelan struktur sesuai dengan kenyataan aslinya, perlu dilakukan pengecekan menggunakan perhitungan manual. Perhitungan manual dilakukan dengan cara meninjau satu kolom yang menggunakan kombinasi $1 \mathrm{D}+1 \mathrm{~L}$, hasil beban aksial dari analisa SAP 2000 v14 harus sesuai dengan perhitungan berat bangunan manual yang memiliki toleransi perbedaan 5 $\%$.

\section{Kontrol Partisipasi Massa}

Menurut SNI 1726 ps 7.9.1, bahwa perhitungan respon dinamik struktur harus sedemikian rupa sehingga partisipasi massa ragam terkombinasi paling sedikit sebesar $90 \%$ dari massa aktual dari masing-masing arah

Dari analisa SAP 2000v14 didapat partisipasi massa arah X sebesar 90,7\% pada moda ke 7 dan partisipasi massa arah Y sebesar 91,0\% pada moda ke 8. Maka dapat disimpulkan analisis struktur yang sudah dilakukan telah memenuhi syarat yang terdapat pada SNI 1726:2012 Pasal 7.9.1 yaitu partisipasi massa ragam terkombinasi paling sedikit sebesar $90 \%$.

\section{Kontrol Waktu Getar Alami Fundamental}

Untuk mencegah pengunaan struktur gedung yang terlalu fleksibel, nilai waktu getar alami fundamental (T) dari struktur gedung harus dibatasi.

Dari hasil analisis SAP 2000v14 didapatkan nilai $\mathrm{T}=$ 1,582 s. Maka berdasarkan kontrol waktu getar alami fundamental nilai $\mathrm{T}$ masih lebih kecil dari $\mathrm{T}_{\mathrm{a}} \max =2,158 \mathrm{~s}$. Jadi analisis struktur Hotel Holiday Inn Express Surabaya masih memenuhi persyaratan Pasal 7.8.2 SNI 1726:2012.

\section{Kontrol Nilai Akhir Respon Spektrum}

Dari hasil analisis menggunakan program SAP 2000 v14 didapatkan nilai gaya geser dasar (base shear) sebagai berikut:

Tabel 5.1

Gaya Geser Dasar Akibat Beban Gempa

\begin{tabular}{ccccc}
\hline \hline OutputCase & CaseType & StepType & GlobalFX & GlobalFY \\
\hline Text & Text & Text & Kgf & Kgf \\
GEMPA X & LinRespSpec & Max & 287082,9 & 98246,08 \\
GEMPA Y & LinRespSpec & Max & 86173,42 & 327303,9 \\
\hline \hline
\end{tabular}

Kontrol nilai akhir respon:

- Gempa arah X:

$$
\begin{array}{ll}
\mathrm{V}_{\text {dinamik }} & \geq 85 \% \cdot \mathrm{V}_{\text {statik }} \\
287082,9 \mathrm{~kg} & \geq 85 \% .494980,9989 \mathrm{~kg} \\
287082,9 \mathrm{~kg} & <420733,849 \mathrm{~kg} \rightarrow \text { NOT OK }
\end{array}
$$

- Gempa arah Y:

$$
\begin{aligned}
& \mathrm{V}_{\text {dinamik }} \geq 85 \% \cdot \mathrm{V}_{\text {statik }} \\
& 327303,9 \mathrm{~kg} \geq 85 \% \cdot 494980,9989 \mathrm{~kg} \\
& 327303,9 \mathrm{~kg} \quad<420733,849 \mathrm{~kg} \rightarrow \text { NOT OK } \\
& \text { Maka harus diperbesar dengan faktor skala } \\
& 0,85 . \frac{C s . W}{V} .
\end{aligned}
$$

\begin{tabular}{|c|c|c|c|c|c|c|c|}
\hline Lantai & $\begin{array}{l}\text { Elevasi } \\
(\mathrm{m})\end{array}$ & $\begin{array}{c}\text { Tinggi } \\
\text { Lantai }(\mathrm{m}) \\
\end{array}$ & $\begin{array}{c}\text { Simpangan } \\
(\mathrm{mm})\end{array}$ & $\begin{array}{l}\text { Simpangan } \\
\text { diperbesar }\end{array}$ & $\begin{array}{c}\text { Simpangan antar } \\
\text { lantai }(\mathrm{mm})\end{array}$ & \begin{tabular}{|c|}
$\begin{array}{c}\text { Simpangan ijin antar } \\
\text { lantai }(\mathrm{mm})\end{array}$ \\
\end{tabular} & Ket \\
\hline \multirow[t]{2}{*}{$\mathrm{i}$} & $\mathrm{hi}$ & $h_{\mathrm{sx}}$ & 6e & 6 & $\Delta$ & $\Delta \mathrm{a}$ & \\
\hline & & hi-h(i-1) & & бe $\mathrm{xCd}_{\mathrm{d}}$ & $\Delta \mathrm{i}-\Delta(\mathrm{i}-1)$ & $0,02 * h_{\mathrm{sx}}$ & \\
\hline Ground & 0 & 0 & 0 & 0 & 0 & 0 & $\mathrm{OK}$ \\
\hline 1 & 3,5 & 3,5 & 2,115 & 8,460 & 8,460 & 70 & $\mathrm{OK}$ \\
\hline 2 & 7,7 & 4,2 & 8,754 & 35,016 & 26,556 & 84 & $\mathrm{OK}$ \\
\hline 3 & 12,5 & 4,8 & 18,325 & 73,300 & 38,284 & 96 & $\mathrm{OK}$ \\
\hline 4 & 15,9 & 3,4 & 24,747 & 98,988 & 25,688 & 68 & $\mathrm{OK}$ \\
\hline 5 & 19,3 & 3,4 & 30,813 & 123,252 & 24,264 & 68 & $\mathrm{OK}$ \\
\hline 6 & 22,7 & 3,4 & 36,586 & 146,344 & 23,092 & 68 & $\mathrm{OK}$ \\
\hline 7 & 26,1 & 3,4 & 42,057 & 168,228 & 21,884 & 68 & $\mathrm{OK}$ \\
\hline 8 & 29,5 & 3,4 & 47,183 & 188,732 & 20,504 & 68 & OK \\
\hline 9 & 32,9 & 3,4 & 51,937 & 207,748 & 19,016 & 68 & $\mathrm{OK}$ \\
\hline 10 & 36,3 & 3,4 & 56,238 & 224,952 & 17,204 & 68 & $\mathrm{OK}$ \\
\hline 11 & 39,7 & 3,4 & 60,152 & 240,608 & 15,656 & 68 & $\mathrm{OK}$ \\
\hline 12 & 43,1 & 3,4 & 63,670 & 254,680 & 14,072 & 68 & $\mathrm{OK}$ \\
\hline 13 & 46,5 & 3,4 & 66,777 & 267,108 & 12,428 & 68 & $\mathrm{OK}$ \\
\hline 14 & 49,9 & 3,4 & 69,498 & 277,992 & 10,884 & 68 & $\mathrm{OK}$ \\
\hline atap & 53,6 & 3,7 & 72,202 & 288,808 & 10,816 & 74 & OK \\
\hline top atap & 58,25 & 4,65 & 75,335 & 301,340 & 12,532 & 93 & $\mathrm{OK}$ \\
\hline
\end{tabular}

\begin{tabular}{|c|c|c|c|c|c|c|c|}
\hline Lantai & $\begin{array}{c}\begin{array}{l}\text { Elevasi } \\
(\mathrm{m})\end{array} \\
\end{array}$ & \begin{tabular}{|c|} 
Tinggi \\
Lantai $(\mathrm{m})$ \\
\end{tabular} & $\begin{array}{c}\begin{array}{c}\text { Simpangan } \\
(\mathrm{mm})\end{array} \\
\end{array}$ & $\begin{array}{l}\text { Simpangan } \\
\text { diperbesar } \\
\end{array}$ & $\begin{array}{c}\text { Simpangan antar } \\
\text { lantai }(\mathrm{mm})\end{array}$ & \begin{tabular}{|c|}
$\begin{array}{c}\text { Simpangan ijin antar } \\
\text { lantai }(\mathrm{mm})\end{array}$ \\
\end{tabular} & Ket \\
\hline $\mathrm{i}$ & $\mathrm{hi}$ & hsx & $6 e$ & 6 & $\Delta$ & \begin{tabular}{|c|}
$\Delta \mathrm{a}$ \\
\end{tabular} & \\
\hline & & hi-h(i-1) & & $6 e \times C d$ & $\Delta \mathrm{i}-\Delta(\mathrm{i}-1)$ & $0,02^{*}$ hsx & \\
\hline Ground & 0 & 0 & 0 & 0 & 0 & 0 & OK \\
\hline 1 & 3,5 & 3,5 & 1,646 & 6,584 & 6,584 & 70 & OK \\
\hline 2 & 7,7 & 4,2 & 6,653 & 26,612 & 20,028 & 84 & OK \\
\hline 3 & 12,5 & 4,8 & 13,616 & 54,464 & 27,852 & 96 & OK \\
\hline 4 & 15,9 & 3,4 & 18,157 & 72,628 & 18,164 & 68 & OK \\
\hline 5 & 19,3 & 3,4 & 22,458 & 89,832 & 17,204 & 68 & $\mathrm{OK}$ \\
\hline 6 & 22,7 & 3,4 & 26,609 & 106,436 & 16,604 & 68 & $\mathrm{OK}$ \\
\hline 7 & 26,1 & 3,4 & 30,618 & 122,472 & 16,036 & 68 & $\mathrm{OK}$ \\
\hline 8 & 29,5 & 3,4 & 34,473 & 137,892 & 15,420 & 68 & $\mathrm{OK}$ \\
\hline 9 & 32,9 & 3,4 & 38,177 & 152,708 & 14,816 & 68 & OK \\
\hline 10 & 36,3 & 3,4 & 41,649 & 166,596 & 13,888 & 68 & $\mathrm{OK}$ \\
\hline 11 & 39,7 & 3,4 & 44,878 & 179,512 & 12,916 & 68 & $\mathrm{OK}$ \\
\hline 12 & 43,1 & 3,4 & 47,836 & 191,344 & 11,832 & 68 & $\mathrm{OK}$ \\
\hline 13 & 46,5 & 3,4 & 50,502 & 202,008 & 10,664 & 68 & $\mathrm{OK}$ \\
\hline 14 & 49,9 & 3,4 & 52,897 & 211,588 & 9,580 & 68 & OK \\
\hline atap & 53,6 & 3,7 & 55,335 & 221,340 & 9,752 & 74 & OK \\
\hline top atap & 58,25 & 4,65 & 58,142 & 232,568 & 11,228 & 93 & OK \\
\hline
\end{tabular}

\section{Kontrol Batas Simpangan (Drift)}

Pembatasan simpangan antar lantai suatu struktur bertujuan untuk mencegah kerusakan non-struktur dan ketidaknyamanan penghuni.
Tabel 5.3

Kontrol Simpangan Arah Y Akibat Gempa Arah Y

\section{PERENCANAAN STRUKTUR PRIMER}

\section{A. Link}

Balok link direncanakan menggunakan profil WF $500 \mathrm{x}$ 200 x 10 x 16. Hasil dari output SAP 2000 diperoleh gaya dalam sebesar:

$$
\begin{aligned}
& \mathrm{e}=150 \mathrm{~cm} \quad<2,6 \mathrm{Mp} / \mathrm{Vp}=1,94 \mathrm{~cm} \\
& \alpha=0,014 \text { radian }<\alpha \text { maks }=0,055 \text { radian } \\
& \mathrm{Nu}=35051,07 \mathrm{~kg}<0,15 \mathrm{Ny}=42825 \mathrm{~kg} \\
& \mathrm{Vu}=53909,64 \mathrm{~kg}<\varnothing \mathrm{Vn}=62891,8 \mathrm{~kg}
\end{aligned}
$$

Untuk pengaku dengan panjang link $<1,6 . \mathrm{Mp} / \mathrm{Vp}$, harus direncanakan memiliki pengaku antara. Untuk $\alpha=$ 0,048 radian maka dipasang pengaku antara dengan jarak 30 $\mathrm{cm}$.

\section{B. Balok diluar link}

Balok link direncanakan menggunakan profil WF $500 \mathrm{x}$ $200 \times 10 \times 16$. Berdasarkan SNI 03-1729-2002 Pasal 15.13.6.2, kuat perlu balok yang terletak diluar link harus ditentukan berdasarkan gaya- gaya yang ditimbulkan paling tidak 1,1 kali kuat geser nominal link sebesar Ry.Vn. Kontrol interaksi geser lentur yang terjadi:

$$
\begin{aligned}
& \frac{M u}{\phi M n}+0,625 \frac{V u}{\phi V n} \leq 1,375 \\
& 1,336<1,375 \rightarrow \mathrm{OK}
\end{aligned}
$$

\section{Bresing}

Bresing direncanakan menggunakan WF 300 x 300 x 10 x 15,dengan kuat kombinasi aksial dan lentur perlu batang bresing harus direncanakan berdasarkan gaya aksial dan 
momen lentur yang di timbulkan oleh link yaitu sebesar 1,25 x Ry x Vn. Kontrol interaksi aksial lentur

$$
\frac{P_{r}}{P_{c}}+\frac{8}{9}\left[\frac{M_{r x}}{\phi \mathrm{M} n}+\frac{M_{r y}}{\phi \mathrm{M} n}\right]=0,724<1,0
$$

\section{Balok}

Balok direncanakan menggunakan profil WF 600 x 200 x 10 x 15. Dari output SAP 2000 diperoleh gaya dalam yang dipakai dalam desain adalah:

$$
\begin{aligned}
& \mathrm{Mu}=39003,5 \mathrm{~kg} \cdot \mathrm{m}<\varnothing \mathrm{Mn}=57041,4 \mathrm{~kg} \cdot \mathrm{m} \\
& \mathrm{Vu}=16254,3 \mathrm{~kg} \geq \varnothing \mathrm{Vn}=89400 \mathrm{~kg} \\
& \delta \quad=0,1406 \mathrm{~cm} \leq \delta \mathrm{ijin}=1,665 \mathrm{~cm}
\end{aligned}
$$

\section{E. Kolom komposit:}

Kolom direncankan menggunakan CFT 700 x 700 × 25 dengan kontrol kuat nominal penampang sebagai berikut:

Dikarenakan $\frac{P_{r}}{P_{c}}>0,2$, maka rumus interaksi aksial dan momen digunakan rumus yang terdapat pada SNI 031729-2002 Pasal 12.5, Persamaan 12.5-1, yaitu sebagai berikut:

\begin{tabular}{|c|c|c|c|}
\hline ELEMEN & LANTAI & ARAH & $\begin{array}{c}\text { PROFIL YANG } \\
\text { DIGUNAKAN }\end{array}$ \\
\hline \multirow{8}{*}{ Balok Induk } & Top atap & $\mathrm{x}$ & WF $400 \times 200 \times 8 \times 13$ \\
\hline & & $\mathrm{y}$ & \\
\hline & Atap & $\mathrm{x}$ & WF $500 \times 200 \times 9 \times 14$ \\
\hline & & $\mathrm{y}$ & \\
\hline & $2-14$ & $\mathrm{x}$ & WF $600 \times 200 \times 10 \times 15$ \\
\hline & & $\mathrm{y}$ & \\
\hline & 1 & $\mathrm{x}$ & WF $600 \times 200 \times 11 \times 17$ \\
\hline & & $\mathrm{y}$ & \\
\hline \multirow{4}{*}{ Kolom } & $1-8$ & - & CFT $700 \times 700 \times 25$ \\
\hline & 9 - top atap & - & CFT $600 \times 600 \times 25$ \\
\hline & Top atap & $\mathrm{x}$ & WF $400 \times 200 \times 8 \times 13$ \\
\hline & & $\mathrm{y}$ & \\
\hline \multirow{6}{*}{ Link } & Atap & $\mathrm{x}$ & WF $400 \times 200 \times 8 \times 13$ \\
\hline & & $\mathrm{y}$ & \\
\hline & $2-14$ & $\mathrm{x}$ & WF $500 \times 200 \times 10 \times 16$ \\
\hline & & $\mathrm{y}$ & \\
\hline & 1 & $\mathrm{x}$ & WF $500 \times 200 \times 10 \times 16$ \\
\hline & & $\mathrm{y}$ & \\
\hline \multirow{8}{*}{$\begin{array}{l}\text { Balok di } \\
\text { luar Link }\end{array}$} & Top atap & $\mathrm{x}$ & WF $400 \times 200 \times 8 \times 13$ \\
\hline & & $\mathrm{y}$ & \\
\hline & Atap & $\mathrm{x}$ & WF $400 \times 200 \times 8 \times 13$ \\
\hline & & $\mathrm{y}$ & \\
\hline & $2-14$ & $\mathrm{x}$ & WF $500 \times 200 \times 10 \times 16$ \\
\hline & & $\mathrm{y}$ & \\
\hline & 1 & $\mathrm{x}$ & WF $500 \times 200 \times 10 \times 16$ \\
\hline & & $\mathrm{y}$ & \\
\hline \multirow[t]{2}{*}{ Bresing } & Top atap & $\mathrm{x}$ & WF $250 \times 250 \times 9 \times 14$ \\
\hline & & $\mathrm{y}$ & \\
\hline
\end{tabular}

$$
\begin{aligned}
\frac{P_{r}}{P_{c}}+\frac{8}{9}\left[\frac{M_{r x}}{\phi \mathrm{M} n}+\frac{M_{r y}}{\phi \mathrm{M} n}\right] & \leq 1,0 \\
0,497+\frac{8}{9}\left[\frac{19594,338}{307125}+\frac{81186,399}{307125}\right] & \leq 1,0 \\
0,818 \quad & <1,0 \rightarrow \mathrm{OK}
\end{aligned}
$$

Tabel 6.1

Rekap Dimensi Struktur Primer

\begin{tabular}{ccc}
\hline \hline Atap & $\mathrm{x}$ & WF $250 \times 250 \times 9 \times 14$ \\
& $\mathrm{y}$ & \\
$2-14$ & $\mathrm{x}$ & WF $300 \times 300 \times 10 \times 15$ \\
& $\mathrm{y}$ & \\
1 & $\mathrm{x}$ & WF $300 \times 300 \times 10 \times 15$ \\
\hline \hline
\end{tabular}

\section{PERENCANAAN SAMBUNGAN}

\section{A. Sambungan kolom CFT 700x700x25 dengan kolom CFT $600 \times 600 \times 25$}

Sambungan kolom CFT 700x700x25 dengan kolom CFT $600 \times 600 \times 25$ direncanakan pada lantai 1 menggunakan las tumpul penetrasi penuh dengan mutu $\mathrm{F}_{\mathrm{e} 70 \mathrm{xx}}$. Gaya-gaya yang bekerja pada sambungan adalah akibat dari beban mati dan beban seismik akibat komponen vertikal. Sambungan ditempatkan pada posisi tengah dari ketinggian lantai.

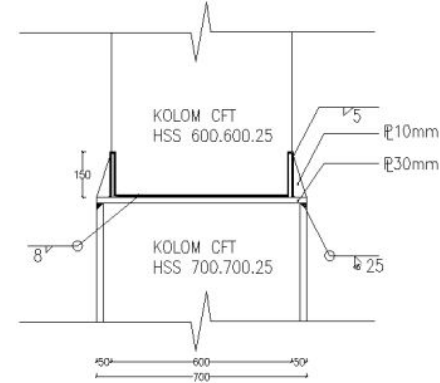

Gambar 7.1 Detail Sambungan Kolom CFT 700.700.25.25 dengan Kolom CFT 700.700.25.2.

\section{B. Sambungan Kolom dengan Balok Induk}

Sambungan pada kolom dengan balok induk direncanakan menggunakan 2 jenis yaitu sambungan pen geser sebagai penumpu pada saat proses pengelasan dan sambungan rigid dengan alat sambung las dan baut sebagai penumpu beban. Sambungan las yang digunakan adalah tipe las $\mathrm{F}_{\mathrm{e} 70 \mathrm{xx}}$.

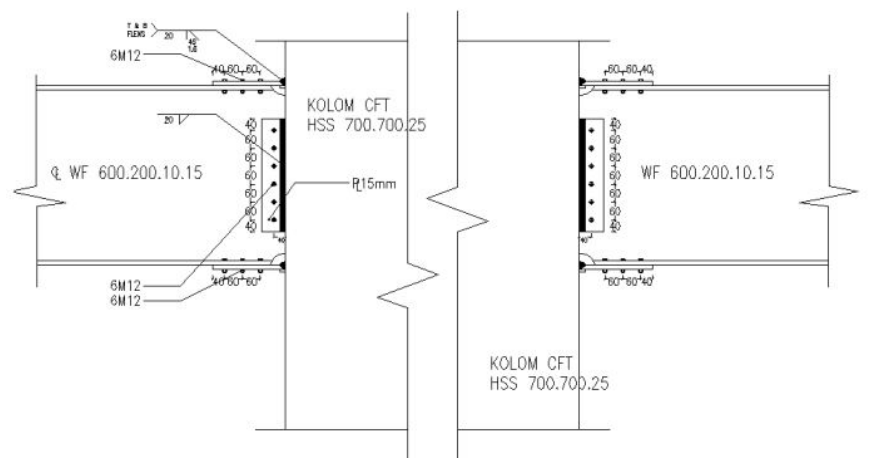

Gambar 7.2 Detail Sambungan Kolom dengan Balok Induk

\section{Sambungan Batang Bresing}

Kuat perlu sambungan batang bresing ke balok harus ditentukan lebih besar atau sama dengan kuat nominal batang bresing yaitu 1,25. Ry . Vn. Dimana Vn adalah kuat geser nominal link yang diambil dari nilai terkecil antara $\mathrm{Vp}$ dengan $\frac{2 M p}{e}$. Digunakan sambungan las dengan mutu $\mathrm{F}_{\mathrm{E} 70 \mathrm{XX}}$ dan mutu baut A325. 


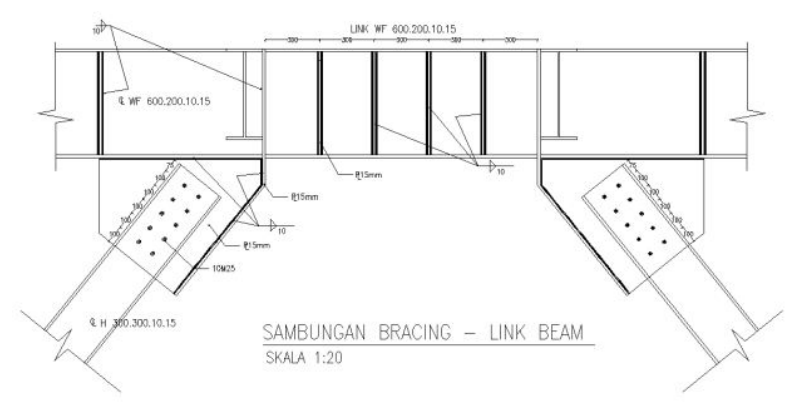

Gambar 7.3 Sambungan Batang Bresing.

\section{Sambungan Kolom CFT dengan Pedestal}

Pedestal direncanakan menggunakan dimensi 800x800. Untuk sambungan kolom CFT 700x700x25 dengan pedestal direncanakan menggunakan las penetrasi penuh dengan mutu $\mathrm{F}_{\mathrm{e} 110 \mathrm{xx}}$.

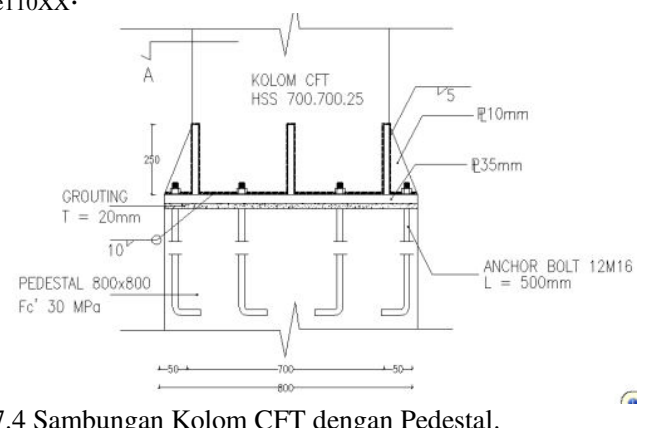

\section{PERENCANAAN PONDASI}

\section{A. Perencanaan Diameter Bore Pile}

Berdasarkan output program bantu SAP 2000 v19 didapatkan besar Qw = 1071,534 ton, dimana $\mathrm{Qw}$ adalah beban yang bekerja di atas tiang:

Diketahui: $F^{\prime} \mathrm{c}=30 \mathrm{MPa}=300 \mathrm{~kg} / \mathrm{cm}^{2}$

Diameter tiang:

$$
\begin{aligned}
\text { Ds } & =2,257 \sqrt{\frac{631718,01}{300}} \\
& =103,57 \mathrm{~cm} \\
& =1,036 \mathrm{~m}
\end{aligned}
$$

Maka diameter borepile yang digunakan adalah 1,2 $\mathrm{m}$ dan diameter pembesaran (Dbell) 2,5 m.

\section{B. Daya Dukung Bore Pile}

Berdasarkan perhitungan daya dukung selimut tiang dan daya dukung di ujung tiang, maka daya dukung borepilenya adalah sebagai berikut:

$$
\begin{aligned}
& \mathrm{Q}_{\mathrm{L}}=\mathrm{Qp}+\mathrm{Qs} \\
&=3268,513+316,672 \\
&=3585,186 \text { ton } \\
& \mathrm{Q}_{\mathrm{ijin}} \quad \frac{Q L}{S F} \\
&=\frac{3585,186}{3}=1195,062 \text { ton } \\
& \mathrm{Qw} \quad<\text { Qijin } \\
& 1071,534 \text { ton }<844,565 \text { ton } \rightarrow \text { OK }
\end{aligned}
$$

\section{KESIMPULAN DAN SARAN}

\section{A. Kesimpulan}

Dari hasil perhitungan dan analisis yang telah dilakukan, maka dapat diambil kesimpulan sebagai berikut:

1. Dari hasil perhitungan struktur sekunder didapatkan :

a. Pelat lantai menggunakan bondek SUPER FLOOR DECK $\mathrm{t}=0,75 \mathrm{~mm}$, dengan 2 macam pelat.

b. Balok anak menggunakan profil WF dengan 4 macam dimensi.

c. Balok lift menggunakan profil WF dengan 2 macam dimensi.

d. Balok tangga menggunakan profil L dan WF dengan 3 macam dimensi.

2. Dari hasil perhitungan struktur primer didapatkan :

a. Balok menggunakan profil WF dengan 4 macam dimensi.

b. Kolom menggunakan komposit profil CFT dengan 2 macam dimensi.

c. Link menggunakan profil WF dengan 2 macam dimensi dengan panjang link 1,2 $\mathrm{m}$ dan 1,5 $\mathrm{m}$.

d. Balok luar link menggunakan profil WF dengan 2 macam dimensi.

e. Bresing menggunakan profil WF dengan 2 macam dimensi.

3. Permodelan analisis struktur menggunakan program bantu SAP 2000v14, dengan 4 kontrol desain dan bangunan telah memenuhi persyaratan desain.

4. Dalam perencanaan ini, sambungan yang digunakan adalah sambungan las dan baut.

5. Pondasi struktur menggunakan tiang bor (borepile) diameter $120 \mathrm{~cm}$ dengan kedalaman $25 \mathrm{~m}$ berdasarkan hasil penyelidikan tanah SPT (Standard Penetration Test). Tulangan yang digunakan pada pondasi borepile adalah 26 D25 dengan sengkang D16-45 mm.

6. Hasil dari perencanaan struktur dapat dilihat pada lampiran gambar berupa gambar teknik.

\section{B. Saran}

Sebaiknya dilakukan studi yang mempelajari tentang perencanaan struktur bresing eksentrik lebih lanjut dengan mempertimbangkan aspek teknis, ekonomi, dan estetika, diutamakan untuk perencanaan struktur yang diharapkan mampu memenuhi persyaratan yang telah ditetapkan dalam peraturan baik SNI maupun AISC.

\section{DAFTAR PUSTAKA}

E. Wahyuni and Y. Tethool, "Effect of Vierendeel Panel Width and Vertical Truss Spacing Ratio in Staggered Truss Framing System Under Earthquake Loads," Int. J. Civ. Eng., vol. 13, no. 2, pp. 213-221, 2015.

[2] Y. Budiono, "Perilaku Link Panjang Dengan Pengaku Diagonal Badan Pada Sistem Struktur Rangka Baja Tahan Gempa," in Seminar dan Pameran HAKI, 2011.

[3] American Institute of Steel Construction, "Seismic Provision for Structural Steel Buildings," 2010.

[4] H. Moestopo, M. Yudi, "Kajian Kinerja Link Yang Dapat Diganti Pada Struktur Rangka Baja Berpengaku Eksentrik Tipe Split-K," in Seminar dan Pameran HAKI, 2006. 